\title{
Análise farmacognóstica e atividade antibacteriana de extratos vegetais empregados em formulação para a higiene bucal
}

\author{
Cynthia Helena Gontijo Cordeiro ${ }^{1}$, Luis Vitor Silva do Sacramento ${ }^{1 *}$, Marcos Antônio Corrêa ${ }^{2}$, \\ Antonio Carlos Pizzolitto 3 , Taís Maria Bauab ${ }^{4}$
}

\footnotetext{
${ }^{1}$ Departamento de Princípios Ativos Naturais e Toxicologia, Faculdade de Ciências Farmacêuticas, UNESP, ${ }^{2}$ Departamento de Fármacos e Medicamentos, Faculdade de Ciências Farmacêuticas, UNESP, ${ }^{3}$ Departamento de Análises Clínicas, Faculdade de Ciências Farmacêuticas, UNESP, ${ }^{4}$ Departamento de Ciências Biológicas, Faculdade de Ciências Farmacêuticas, UNESP
}

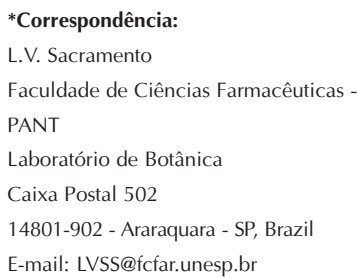

A utilização de extratos vegetais vem se tornando uma alternativa importante para a prevenção de doenças periodontais. Este trabalho objetivou desenvolver uma formulação de enxagüatório bucal, contendo, em associação, extratos hidroalcoólicos de Rosmarinus officinalis, Plantago major, Tabebuia impetiginosa, Achillea millefollium $e$ Nasturtium officinale; avaliar sua composição farmacognóstica e sua atividade antibacteriana, como também da fórmula proposta. Foram realizados estudos de pré-formulação e análises farmacognósticas para as espécies vegetais. A atividade antibacteriana in vitro foi observada por meio dos métodos de difusão em disco de papel, por hole- plate e por template, frente a Staphylococcus aureus, Bacillus subtilis, Escherichia coli, Enterococcus faecalis e Pseudomonas aeruginosa. $A$ concentração inibitória mínima (CIM) foi determinada por meio do método de macrodiluições sucessivas em caldo. Os resultados obtidos apresentaram-se de acordo com o histórico farmacognóstico das drogas estudadas. Todas as bactérias foram inibidas pelos extratos, observando-se que as espécies $\mathrm{S}$. aureus e $\mathrm{B}$. subtilis mostraram, aparentemente, maior sensibilidade. A CIM variou, em relação a sensibilidade de cada espécie bacteriana estudada, de 312,5 $\mu \mathrm{L} / \mathrm{mL}$ a $1250 \mu \mathrm{L} / \mathrm{mL}$ para os extratos vegetais e de $625 \mu \mathrm{L} / \mathrm{mL}$ a $2500 \mu \mathrm{L} / \mathrm{mL}$ para o enxaguatório bucal. São necessários estudos complementares para a confirmação da eficácia deste produto e sua utilização na prevenção de doenças periodontais.
Unitermos

- Nasturtium

- Rosmarinus

- Tabebuia

- Plantago

- Achillea

- Enxaguatório bucal

- Atividade antibacteriana 


\section{INTRODUÇÃO}

As plantas medicinais constituem importantes recursos terapêuticos para o tratamento de doenças, principalmente das populações das nações em desenvolvimento. Servem tanto à conhecida "medicina caseira", que faz parte da cultura popular destes países, como de matéria-prima para elaboração de medicamentos fitoterápicos ou extração de compostos químicos com atividade terapêutica (Freitas, 1999). A fitoterapia existe principalmente no mercado informal, o que representa grande perigo à saúde da população, pois neste caso, sua comercialização ocorre desconsiderando os aspectos relativos ao controle de identidade e/ou pureza. É indiscutível a necessidade de um maior e melhor controle nesse ramo cosmético e farmacêutico, pois os fitoterápicos representam uma alternativa economicamente viável à população (Bendazzoli, 2000).

A abrangência da utilização de fitoterápicos e de plantas medicinais é vasta e engloba fins variados, também em relação à saúde bucal. Considerando as doenças periodontais, pode-se defini-las como, um processo infeccioso que resulta em uma potente resposta inflamatória (Monteiro et al., 2002). Alguns microorganismos, tidos como patógenos periodontais, possuem a capacidade de implantar-se no sulco gengival, produzindo substâncias tóxicas que degeneram o tecido periodontal (Rubira, 1993). A susceptibilidade individual e as influências ambientais estão diretamente envolvidas neste processo, onde a gengivite e a periodontite representam as formas mais comuns da doença (Figueiredo et al., 2002).

Os dados sobre a prevalência das doenças periodontais no Brasil, são alarmantes, estando próxima de cem por cento (Oppermann, Kuchnbecker, 2001), abrangendo, sobretudo crianças de diferentes regiões. A mudança desta situação implicaria na adoção das práticas individuais de higiene bucal (Pereira et al., 1994), onde seria também necessário o planejamento de programas preventivos e da terapia periodontal básica (Marcantonio, Santos, 1998).

O controle do biofilme bacteriano dentro das diversas especialidades odontológicas é de grande importância, pois aponta tanto para a prevenção, como para o tratamento, da cárie e de doenças periodontais. Com a finalidade de auxiliar os métodos convencionais de higiene bucal (escovação, fio ou fita dental) muitos agentes químicos vêm sendo estudados, entre eles antibióticos, compostos quaternários de amônio, acetato e gluconato de clorexidina e outros (Oliveira et al., 1998). No entanto, o uso freqüente e por longo prazo da clorexidina, apresenta alguns efeitos indesejáveis (Rey, 1999). Outros ativos, como os antiinflamatórios e anti-sépticos, também vêm sendo utilizados amplamente para afecções da mucosa bucal.

A eficácia de plantas medicinais, como componentes tanto nos géis dentifrícios, como nos enxaguatórios bucais, tem sido investigada para o tratamento de gengivites. Os resultados sugerem que os ingredientes de origem vegetal podem ser empregados como apoio à terapia das doenças periodontais e como profilaxia de rotina (Willershausen et al., 1994).

Dados sobre a atividade antibacteriana de extratos vegetais e fitofármacos, avaliada frente a microorganismos sensíveis e resistentes a antibióticos, bem como o possível efeito sinérgico da associação entre antibióticos e extratos vegetais, são relevantes, permitindo concluir que estudos mais detalhados sobre o uso terapêutico das plantas devem ser intensificados (Nascimento et al., 2000).

Trevizani (2002) observou redução do índice de sangramento gengival em indivíduos que fizeram uso de gel dentifrício contendo, em associação, extratos hidroalcoólicos de Rosmarinus officinalis, Plantago major, Tabebuia impetiginosa, Achillea millefollium e Nasturtium officinale, sugerindo efeito antigengivite, através de possível ação antiinflamatória de seus componentes ativos e/ou por alteração da qualidade do biofilme dento-bacteriano.

Outros estudos têm demonstrado a eficácia destas plantas, cuja utilização está difundida entre a população, reforçando a necessidade de se intensificarem as pesquisas em relação às atividades antiinflamatórias, anti-sépticas, cicatrizantes e analgésicas, quando usadas isoladamente, ou em associações, o que seria útil para prevenção e tratamento de doenças periodontais (Krivenko et al., 1989; Almeida, 1993; Teske, Trentini, 1995; Oliveira et al., 1998; Goda et al., 1999; Matos, 2000; Samuelsen, 2000; Lorenzi, Matos, 2002).

A utilização destes produtos fitoterápicos, economicamente mais viáveis, mostra-se como uma alternativa interessante, contribuindo para melhorar o acesso da população aos cuidados com a prevenção e tratamento de doenças periodontais.

Este estudo teve como objetivos desenvolver uma formulação de enxagüatório bucal contendo em associação, os extratos hidroalcoólicos das espécies vegetais $R$. officinalis (Alecrim), P. major (Tanchagem), $T$. impetiginosa (Ipê-roxo), A. millefollium (Mil-folhas) e $N$. officinale (Agrião); realizar a avaliação farmacognóstica das referidas espécies, tanto para a droga vegetal pulverizada como para os extratos hidroalcoólicos; e, ainda avaliar a atividade antibacteriana in vitro da mistura de extratos utilizada, bem como da formulação proposta. 


\section{MATERIAL E MÉTODOS}

\section{Preparo do material vegetal}

As espécies vegetais utilizadas foram colhidas entre os meses de abril e junho de 2003, e identificadas no Laboratório de Botânica da FCF/UNESP Campus de Araraquara. O material vegetal utilizado no preparo dos extratos hidroalcoólicos, foi colhido no Horto de Plantas Medicinais e Tóxicas da mesma unidade, exceto $T$. impetiginosa (Ipê-roxo) que foi colhida no Jardim do Campus da UNESP de Araraquara e o N. officinale (Agrião) que foi adquirido no comércio. Foram utilizados órgãos aéreos para as cinco espécies referidas (flores para a espécie de ipê roxo e folhas para as demais).

O material fresco de $P$. major (Tanchagem), depois de colhido, foi submetido à lavagem, e posterior imersão em solução de hipoclorito de sódio $0,01 \%$, a fim de se promover sua desinfecção. Após este procedimento, o material vegetal foi submetido a secagem prévia, por aproximadamente 24 horas, à temperatura ambiente, sobre bancadas, previamente limpas, sanitizadas e revestidas com papel absorvente, seguindo-se à secagem, em estufa de circulação de ar, a $45^{\circ} \mathrm{C}$, por 72 horas. Após este processo, a planta foi colocada em moinho de bolas, por aproximadamente 3 horas, para se obter uma granulometria adequada. Devido à falta de padronização granulométrica para a extração por turbólise, optou-se pela classificação para pó grosso preconizado na United States Pharmacopeia 23, que estabelece um tamanho médio de partícula de $0,84 \mathrm{~mm}$. O material fresco de cada uma das outras espécies vegetais empregadas neste estudo ( $N$. officinale (Agrião), R. officinalis (Alecrim), T. impetiginosa (Ipê-roxo), $A$. millefollium (Mil-folhas)) foi submetido às mesmas etapas já descritas.

\section{Preparo dos extratos vegetais}

Os extratos vegetais foram preparados tomando-se $10 \%(\mathrm{p} / \mathrm{p})$ da respectiva planta (N. officinale (Agrião), $R$. . officinalis (Alecrim), T. impetiginosa (Ipê-roxo), $A$. millefollium (Mil-folhas)), separadamente e adicionandose $90 \%(\mathrm{p} / \mathrm{p})$ de etanol $70^{\circ} \mathrm{GL}(\mathrm{v} / \mathrm{v})$. Procedeu-se à extração por turbólise, com tempo de agitação de 10 minutos, divididos em intervalos de 5 minutos, entre os quais, um período de descanso de 5 minutos. Durante o processo de preparo do extrato a temperatura foi controlada com o auxílio de um termômetro de maneira a garantir que não ultrapassasse $40^{\circ} \mathrm{C}$. Em seguida, procederam-se duas filtrações a vácuo. Os extratos hidroalcoólicos obtidos foram acondicionados em frascos de vidro âmbar, sob refrigeração a $4^{\circ} \mathrm{C}$, para serem empregados na realização dos ensaios previstos. Inicialmente foram preparados cerca de $500 \mathrm{~mL}$ de extrato de cada espécie vegetal para que pudessem ser realizados os estudos farmacognósticos de interesse e os estudos de pré-formulação. Ao longo do desenvolvimento do trabalho foram preparados mais extratos de acordo com o requerido para a realização dos estudos.

A mistura de extratos a ser empregada na formulação foi preparada tomando-se $4 \%(\mathrm{p} / \mathrm{p})$ do extrato hidroalcoólico de P. major e $2 \%(\mathrm{p} / \mathrm{p})$ dos demais extratos previamente obtidos.

\section{Análise farmacognóstica}

As análises farmacognósticas foram realizadas a fim de se detectar a presença de compostos de interesse nas diferentes espécies e os testes realizados foram para a identificação de alcalóides, saponinas, antraquinonas e taninos, seguindo-se as metodologias validadas para cada grupo. Foram realizados testes para os vegetais pulverizados e para os extratos hidroalcoólicos.

Os testes para flavonóides consistiram das reações de Shinoda, de Taubock e com cloreto de alumínio. A presença de saponinas foi verificada através do testes de espuma persistente. Para a presença de taninos foram realizadas as reações com gelatina, com sais de ferro e com acetato de chumbo. Para a pesquisa de alcalóides foram realizados os testes com os reativos de Dragendorff, Valser-Mayer, Wagner e de Bertrand. E para antraquinonas foi realizada a Reação de Bornträger e da microsublimação (Mello et al., 1997; Falkenberg et al., 2003).

\section{Elaboração da formulação}

Para o desenvolvimento da fórmula de enxagüatório bucal, foram empregados os seguintes materiais: água destilada (como principal solvente), álcool etílico, flavorizantes, edulcorantes, solubilizantes e a mistura de extratos vegetais hidroalcólicos (nas concentrações de 4\% $(\mathrm{p} / \mathrm{p})$ de extrato de P. major e $2 \%(\mathrm{p} / \mathrm{p})$ dos demais).

Com o intuito de se definir a concentração de cada componente, foram realizados estudos de pré-formulação, entre os quais citam-se os descritos a seguir: testes de solubilidade, empregando-se monoleato de polioxietileno sorbitano em concentrações variadas, como agente solubilizante; testes para se definir a quantidade adequada de edulcorante, dispondo-se de vários, entre eles a sacarina sódica, podendo estar associada ou não, a outros; e testes para se definir a quantidade de flavorizante (aroma 
de pippermint) a ser utilizada.

Além disso, com o intuito de garantir a conservação do produto, foi utilizado como preservante o metilparabeno, na concentração de $0,1 \%$.

\section{Avaliação da atividade antibacteriana}

A avaliação da atividade antibacteriana in vitro foi realizada pelos métodos de difusão em disco de papel, difusão a partir de orifício no meio de cultura (hole plate) e difusão com o uso de template. Verificou-se a sensibilidade das bactérias Gram-positivas e Gram-negativas $P$. aeruginosa (ATCC $\mathrm{n}^{\circ} 27853$ ), E. coli (ATCC $\left.\mathrm{n}^{\circ} 25922\right), S$. aureus (ATCC $\mathrm{n}^{\circ}$ 25923), B. subtilis (ATCC $\mathrm{n}^{\circ}$ 6633), E. faecalis (ATCC $\mathrm{n}^{\circ}$ 10541), frente à mistura de extratos hidroalcoólicos e a formulação de enxaguatório bucal com e sem extratos vegetais.

Para a realização de todas as etapas do estudo, $30 \mathrm{~mL}$ da mistura de extratos, $30 \mathrm{~mL}$ do enxaguatório bucal contendo extratos vegetais e $30 \mathrm{~mL}$ do enxaguatório bucal com e sem extratos vegetais, foram concentrados por evaporação a $40{ }^{\circ} \mathrm{C}$ e o resíduo foi ressuspenso em $3 \mathrm{~mL}$ de etano $170^{\circ} \mathrm{GL}$.

Para o método de difusão usando disco de papel, os mesmos foram preparados a partir de papel Wathman $\mathrm{n}^{\circ} 1$, com $15 \mathrm{~mm}$ de diâmetro e capacidade de absorção de cerca de $50 \mu \mathrm{L}$ de amostra. Foram distribuídos $20 \mathrm{~mL}$ do meio de cultura utilizado, Triptona Soja - TSA (Difco), sobre cada placa $(90 \times 15 \mathrm{~mm})$, sobre os quais foram dispostos os discos de papel embebidos com as amostras. As placas foram incubadas a $36 \pm 1{ }^{\circ} \mathrm{C}$ por 48 horas.

Para a realização do método de difusão por hole plate, foram utilizadas placas preparadas da mesma maneira, sobre as quais foram realizados orifícios com o auxílio de um furador de metal, estéril, de $3 \mathrm{~mm}$ de diâmetro e $5 \mathrm{~mm}$ de altura, onde foram colocadas as amostras, correspondentes a um volume de $100 \mu \mathrm{L}$. As placas foram incubadas a $36 \pm 1{ }^{\circ} \mathrm{C}$ por 48 horas.

Para o método de difusão usando template, foi utilizado como controle um disco de papel contendo Cloranfenicol (30 mcg), para comparação dos halos de inibição. As placas de Petri também foram preparadas com meio TSA. Após inoculação da espécie de bactéria, o template foi colocado sobre a placa e as amostras foram distribuídas em seus orifícios, no volume de $50 \mu \mathrm{L}$. As placas foram incubadas a $36 \pm 1^{\circ} \mathrm{C}$ por 48 horas.

Também foi determinada a concentração inibitória mínima (CIM) para as amostras em estudo, por meio do método de diluições sucessivas em meio de cultura líquido. Foram preparadas séries com 8 tubos de cultura contendo caldo Müller Hinton, e nos 7 primeiros, foram concentrações decrescentes de cada amostra $(2500 \mu \mathrm{g} / \mathrm{mL}$ a
$39,0 \mu \mathrm{g} / \mathrm{mL}$ ). O $8^{\circ}$ tubo representava o controle do crescimento da espécie bacteriana. Em cada série de 8 tubos foi inoculada uma das espécies de bactérias em estudo ( $S$. aureus, B. subtilis, E. coli, P. aeruginosa e E. faecalis). A todos os tubos da série foi inoculado o microrganismo $(50 \mu \mathrm{L})$. Foram obtidas dessa maneira, 5 séries de tubos (cada uma correspondente a uma espécie bacteriana) para cada uma das amostras em análise. As concentrações das amostras foram as seguintes:

- para a amostra da mistura de extratos: $2500,00 \mu \mathrm{L} / \mathrm{mL}$; $1250,00 \mu \mathrm{L} / \mathrm{mL} ; 625,00 \mu \mathrm{L} / \mathrm{mL} ; 312,50 \mu \mathrm{L} / \mathrm{mL}$; $156,25 \mu \mathrm{L} / \mathrm{mL} ; 78,12 \mu \mathrm{L} / \mathrm{mL} ; 39,06 \mu \mathrm{L} / \mathrm{mL}$.

- para a amostra de enxaguatório bucal contendo extratos vegetais: $2500,00 \mu \mathrm{L} / \mathrm{mL} ; 1250,00 \mu \mathrm{L} / \mathrm{mL} ; 625,00 \mu \mathrm{L} /$ $\mathrm{mL} ; 312,50 \mu \mathrm{L} / \mathrm{mL} ; 156,25 \mu \mathrm{L} / \mathrm{mL} ; 78,12 \mu \mathrm{L} / \mathrm{mL}$; $39,06 \mathrm{~mL} / \mathrm{mL}$.

- para a amostra de enxaguatório bucal sem extratos vegetais: $2500,00 \mu \mathrm{L} / \mathrm{mL} ; 1250,00 \mu \mathrm{L} / \mathrm{mL} ; 625,00 \mu \mathrm{L} / \mathrm{mL}$; $312,50 \mu \mathrm{L} / \mathrm{mL} ; 156,25 \mu \mathrm{L} / \mathrm{mL} ; 78,12 \mu \mathrm{L} / \mathrm{mL} ; 39,06 \mu \mathrm{L} /$ $\mathrm{mL}$.

A fim de se confirmar o crescimento real da espécie bacteriana em questão (excluindo-se uma possível turvação mecânica), foram realizados repiques em meio TSA com incubação a $35^{\circ} \mathrm{C}$, durante 24 horas, para crescimento, eliminando dessa maneira possíveis interferências de componentes da fórmula, que poderiam causar turvação por precipitação, oferecendo resultados errôneos.

\section{RESULTADOS E DISCUSSÃO}

Em relação às análises farmacognósticas, realizadas com os vegetais pulverizados e com os extratos vegetais, obtiveram-se os resultados mostrados na Tabela I. Entre os grupos químicos pesquisados neste trabalho, cujos resultados estão apresentados na Tabela $\mathrm{I}$, a espécie $N$. officinale (Agrião) apresentou-se positiva apenas para flavonóides, o que confere com a descrição de Almeida (1993); Goda et al. (1999); Lorenzi e Matos (2002).

A espécie $R$. officinalis (Alecrim) apresentou-se positiva para taninos e flavonóides, confirmando sua caracterização fitoquímica que registra para folhas a presença de taninos, flavonóides e alguns ácidos fenólicos (Matos, 2000; Lorenzi, Matos, 2002).

$\mathrm{Na}$ determinação dos grupos químicos encontrados no T. impetiginosa (Ipê-roxo), obteve-se resultado positivo para flavonóides o que também pode ser confirmado pela literatura segundo descrição de Teske e Trentini, (1995); Lorenzi e Matos (2002).

A presença de alcalóides e flavonóides para a espécie P. major (Tanchagem) confirma o descrito por Samuelsem (2000), que se refere aos principais compos- 
TABELA I - Resultados dos testes farmacognósticos empregados para as drogas vegetais em pó e extratos hidroalcólicos

\begin{tabular}{|c|c|c|c|c|c|c|c|c|c|c|}
\hline $\begin{array}{l}\text { Testes de Identificação } \\
\text { Espécie vegetal }\end{array}$ & \multicolumn{2}{|c|}{$\begin{array}{l}\text { Saponinas } \\
\text { Pó Extrato }\end{array}$} & \multicolumn{2}{|c|}{ Taninos } & \multicolumn{2}{|c|}{$\begin{array}{c}\text { Antraquinonas* } \\
\text { Pó Extrato }\end{array}$} & \multicolumn{2}{|c|}{$\begin{array}{l}\text { Alcalóides } \\
\text { Pó Extrato }\end{array}$} & \multicolumn{2}{|c|}{$\begin{array}{r}\text { Flavonóides } \\
\text { PóExtrato }\end{array}$} \\
\hline N. officinale (Agrião) & - & - & - & - & - & - & - & - & + & + \\
\hline R. officinalis (Alecrim) & - & - & + & + & - & - & _ & - & + & + \\
\hline T. impetiginosa (Ipê roxo) & + & - & - & - & - & - & - & - & + & + \\
\hline P. major (Tanchagem) & - & - & - & - & - & - & + & + & + & + \\
\hline A. millefolium (Mil folhas) & + & - & + & + & - & - & - & - & + & + \\
\hline Mistura de extratos & NA & + & NA & + & NA & - & NA & - & NA & + \\
\hline
\end{tabular}

* Livres e glicosiladas; (+) positivo; (-) negativo; (NA) não se aplica

tos químicos, como polissacarídeos, lipídios, derivados do ácido cafeico, flavonóides, glicosídeos iridóides e terpenóides, alcolóides e ácidos orgânicos. Já a $A$. millefollium (Mil-folhas) apresentou resultados positivos para taninos e flavonóides, como descrito por Lorenzi e Matos (2002).

Com relação aos estudos de pré-formulação, a fórmula proposta para o enxaguatório bucal ficou definida como mostrado na Tabela II.

Em se tratando de uma formulação de enxaguatório bucal, a proposta de trabalho foi utilizar a água destilada como principal solvente, minimizando-se a utilização do álcool etílico, resultando, juntamente com outros fatores, na redução do custo da preparação final. Considerando que os extratos vegetais hidroalcoólicos precipitaram na presença de maior conteúdo aquoso, foi necessário garantir sua solubilidade, dispondo-se de um agente solubilizante conhecidamente não tóxico ou, irritante. O agente escolhido foi o monoleato de polioxietileno sorbitano (Prista et al., 1995) o qual, além das características mencionadas mostrou análise sensorial positiva, constituindo um fator importante para se obter um pro- duto de sabor aceitável e agradável, contribuindo para a sua correta utilização. Os testes de solubilidade envolveram o emprego de várias concentrações do tensoativo e permitiram viabilizar a quantidade de extratos vegetais adequada para as possíveis ações terapêuticas (Trevizani, 2002); sua concentração final ficou definida em $0,5 \%$. A quantidade de sacarina utilizada na formulação ficou definida como sendo de $0,025 \%$. O flavorizante escolhido foi o aroma de pippermint, que melhor se adaptou à proposta, na concentração de $0,06 \%$.

Essa formulação apresentou cor esverdeada, mostrando-se límpida, sem a ocorrência de turvação mesmo após ser armazenada sob refrigeração a $4^{\circ} \mathrm{C}$ por três dias e à temperatura ambiente (em torno de $\left.27^{\circ} \mathrm{C}\right)$ pelo mesmo período. Apresentou ainda, odor e sabor de menta, adocicado e $\mathrm{pH}$ de 6,5 a temperatura de $25^{\circ} \mathrm{C}$.

A formulação de enxagüatório bucal não contendo extratos vegetais também apresentou características organolépticas semelhantes às da formulação anterior, de cor verde amarelada, límpida, sem a ocorrência de turvação mesmo após ser armazenada sob refrigeração a $4{ }^{\circ} \mathrm{C}$ por três dias e à temperatura ambiente (em torno de $27^{\circ} \mathrm{C}$ ) também

TABELA II - Formulação do enxaguatório bucal

\begin{tabular}{lccc}
\hline Formulação & INCI name & \multicolumn{2}{c}{ Enxagüatório bucal(\%)/p) } \\
\cline { 3 - 4 } & & $\begin{array}{c}\text { Contendo extratos } \\
\text { vegetais }\end{array}$ & $\begin{array}{c}\text { Não contendo } \\
\text { extratos vegetais }\end{array}$ \\
\hline Etanol 70\% & Alcohol 70\% & NA & 12 \\
Extratos vegetais & - & 12 & NA \\
Aroma de pippermint & Mentha Piperita oil & 0,06 & 0,06 \\
Sacarina sódica & Sodium Saccharin & 0,025 & 0,025 \\
Monoleato de & Polysorbate 80 & 0,50 & 0,50 \\
polixoetileno sorbitano & Methylparaben & 0,1 & 0,1 \\
Metilparabeno & - & NA & 0,24 \\
Solução de corantes & Water & 100 & 100 \\
Água destilada q.s.p. & & &
\end{tabular}


por três dias. Apresentando também, odor e sabor de menta, adocicado e um $\mathrm{pH}$ de 6,2 a temperatura de $25^{\circ} \mathrm{C}$.

Em relação aos estudos de atividade antibacteriana, verificou-se que todas as bactérias foram inibidas pelos extratos utilizados, observando-se que as espécies $S$. aureus e $B$. subtilis apresentaram, aparentemente, maior sensibilidade. O diâmetro dos halos de inibição são dados em milímetros, após 48 horas de incubação, e são apresentados nas Tabelas III, IV e V.
No teste de difusão em disco de papel, os halos de inibição para E. faecalis, $S$. aureus e B. subtilis, mostraram-se maiores, frente à mistura de extratos. Nesta etapa, $P$. aeruginosa apresentou-se resistente frente a todas as amostras.

No teste de difusão por hole-plate observou-se que $P$. aeruginosa, que anteriormente havia apresentado resistência, nesta etapa apresentou halos de inibição consideráveis, principalmente frente à mistura de extratos. Mais uma vez

TABELA III - Halos de inibição obtidos com o teste de difusão em disco

\begin{tabular}{lcccc}
\hline Amostra & Controle etanol & \multicolumn{2}{c}{ Diâmetro dos halos de inibição (mm) } \\
\cline { 3 - 5 } Microrganismo & $\mathbf{7 0} \mathbf{G L}$ & Mistura de extratos & \multicolumn{2}{c}{ Enxagüatório Bucal } \\
\cline { 3 - 5 } & & & $\begin{array}{c}\text { Contendo extratos } \\
\text { vegetais }\end{array}$ & $\begin{array}{c}\text { Não contendo } \\
\text { extratos vegetais }\end{array}$ \\
\hline S. aureus & $\mathrm{R}$ & 19 & $\mathrm{R}$ & $\mathrm{R}$ \\
B. subtilis & $\mathrm{R}$ & 19 & $\mathrm{R}$ & $\mathrm{R}$ \\
P. aeruginosa & $\mathrm{R}$ & $\mathrm{R}$ & $\mathrm{R}$ & $\mathrm{R}$ \\
E. coli & $\mathrm{R}$ & $\mathrm{R}$ & $\mathrm{R}$ & $\mathrm{R}$ \\
E. faecalis & $\mathrm{R}$ & 17 & $\mathrm{R}$ \\
\hline
\end{tabular}

$\mathrm{R}=$ resistente $($ halo $<1 \mathrm{~mm})$

TABELA IV - Halos de inibição obtidos com teste de difusão por hole plate

\begin{tabular}{lcccc}
\hline $\begin{array}{l}\text { Amostra } \\
\text { Microrganismo }\end{array}$ & \begin{tabular}{c} 
Controle etanol \\
\cline { 3 - 4 }
\end{tabular} & $\mathbf{7 0}^{\circ} \mathbf{G L}$ & Mistura de extratos & \multicolumn{2}{c}{ Enxâmetro dos halos de inibição (mm) } \\
\cline { 3 - 5 } & & & $\begin{array}{c}\text { Contendo extrio Bucal } \\
\text { vegetais }\end{array}$ & $\begin{array}{c}\text { Não contendo } \\
\text { extratos vegetais }\end{array}$ \\
\cline { 3 - 5 } & & 9 & 5 & 5 \\
B. subtilis & $\mathrm{R}$ & 13 & 5 & 5 \\
$P$. aeruginosa & $\mathrm{R}$ & 5 & $\mathrm{R}$ & 5 \\
E. coli & $\mathrm{R}$ & 7 & $\mathrm{R}$ & $\mathrm{R}$ \\
E. faecalis & $\mathrm{R}$ & & &
\end{tabular}

TABELA V - Halos de inibição obtidos pelo teste de difusão utilizando template

\begin{tabular}{lcccc}
\hline $\begin{array}{l}\text { Amostra } \\
\text { Microrganismo }\end{array}$ & Cloranfenicol & \multicolumn{2}{c}{ Diâmetro dos halos de inibição (mm) } \\
\cline { 3 - 5 } & & & \multicolumn{2}{c}{ Enxagüatório Bucal } \\
\cline { 3 - 5 } & & & $\begin{array}{c}\text { Contendo extratos } \\
\text { vegetais }\end{array}$ & $\begin{array}{c}\text { Não contendo } \\
\text { extratos vegetais }\end{array}$ \\
\hline S. aureus & 17 & 5 & 5 & 5 \\
B. subtilis & 19 & 7 & 5 & 5 \\
P. aeruginosa & $\mathrm{R}$ & 7 & $\mathrm{R}$ & 5 \\
E. coli & 17 & 7 & $\mathrm{R}$ & $\mathrm{R}$ \\
E. faecalis & 15 & 5 & & 5 \\
\hline
\end{tabular}


os microorganismos $S$. aureus e B. subtilis, apresentaramse mais sensíveis, mostrando um maior halo de inibição.

No teste de difusão utilizando template, os resultados confirmaram os obtidos anteriormente que, em comparação com o cloranfenicol, as espécies $S$. aureus e $B$. subtilis foram as cepas mais sensíveis. Os enxaguatórios bucais (contendo ou não extratos vegetais) também apresentaram certa atividade, porém não foi observada diferença entre os resultados apresentados pela formulação contendo ou não extratos vegetais. A espécie $P$. aeruginosa foi inibida de maneira muito semelhante por todas as amostras. As espécies E. coli e E. faecalis, sofreram certa inibição das amostras, porém de maneira semelhante entre elas, sendo que somente o cloranfenicol inibiu de maneira significativa todas as espécies em estudo, com exceção da espécie $P$. aeruginosa.

Observa-se conforme a literatura, que as bactérias Gram-negativas (P. aeruginosa, E. coli) mostraram-se mais resistentes que as bactérias Gram-positivas $(S$. aureus, $B$. subtilis) que se apresentam mais sensíveis, sendo que a cepa $B$. subtilis foi a mais sensível delas.

Os resultados obtidos neste estudo mostraram que o enxaguatório bucal contendo extratos vegetais foi capaz de inibir o crescimento das bactérias estudadas, porém as espécies que se mostraram mais sensíveis aparentemente foram $S$. aureus e B. subtilis, em meio de cultura TSA, após 48 horas. Embora não exista um padrão de concentração para comparação dos resultados da atividade dos extratos e dos produtos, uma vez que seus princípios ativos ainda não são bem conhecidos, algumas bactérias ensaiadas (principalmente $B$. subtilis e $S$. aureus) apresentaram halos de inibição consideráveis.

Em relação à determinação da CIM, para os tubos nos quais não foi verificada a ocorrência de turvação, foram realizados repiques para meios sólidos, objetivandose verificar a ação bacteriostática. A resistência ou sensibilidade da bactéria em estudo foi registrada e os dados são os que se seguem: observando-se os resultados obtidos, verificou-se que seu valor variou de $312,5 \mu \mathrm{L} / \mathrm{mL}$ a $1250 \mu \mathrm{L} / \mathrm{mL}$ para os extratos vegetais, e de $625 \mu \mathrm{L} / \mathrm{mL}$ a $2500 \mu \mathrm{L} / \mathrm{mL}$ para o enxaguatório bucal contendo extratos vegetais e $625 \mu \mathrm{L} / \mathrm{mL}$ a $2500 \mu \mathrm{L} / \mathrm{mL}$ para enxaguatório bucal sem extratos vegetais (Tabela VI).

Alguns trabalhos já foram realizados utilizando as mesmas espécies vegetais, dentre eles Cowan (1999) que também mostrou a atividade antimicrobiana de $R$. officinalis (Alecrim) e A. millefolium (Mil-folhas). Através de um trabalho de revisão o autor mostra a atividade antimicrobiana de várias espécies vegetais, relacionando as classes de substâncias químicas presentes em extratos obtidos com diferentes solventes (água destilada, metanol e etanol). O autor faz menção ao óleo essencial do Alecrim e sua atividade sobre bactérias Gram-positivas e negativas, vírus, fungos e protozoários, atribuindo a mesma principalmente aos terpenóides. E ainda apresenta atividade sobre vírus e helmintos para a mil-folhas. Nascimento et al. (2000) propuseram a utilização de associação de antibióticos e extratos vegetais, sobre bactérias resistentes, evidenciando a ocorrência de sinergismo, possibilitando assim, que antibióticos individualmente inativos apresentassem ação sobre estas bactérias. Os autores avaliaram a atividade de extratos etanólicos de $R$. officinalis e $A$. millefolium associada à antibióticos, sobre microorganismos resistentes. Foi observado que os extratos apresentaram atividade sobre os microorganismos quando utilizados isoladamente e quando associados em pequenas concentrações aos antibióticos inativos. Sökmen et al. (2003) apresentaram resultados importantes da atividade de outra espécie do gênero Achillea sobre microorganismos, incluindo fungos (duas espécies diferentes) e bactérias (doze espécies diferentes), através da avaliação do extrato metanólico da planta.

Koyama et al. (2000) mostraram que as cascas de $T$. impertiginosa (Ipê-roxo) têm sido muito utilizadas popu-

TABELA VI - Valores de CIM para os produtos analisados

\begin{tabular}{lccc}
\hline Amostra Microrganismo & \multicolumn{2}{c}{ Concentração em $(\boldsymbol{\mu L} / \mathbf{m L})$} \\
\cline { 2 - 4 } & & \multicolumn{2}{c}{ Enxagüatório bucal } \\
\cline { 3 - 4 } & & $\begin{array}{c}\text { Contendo extratos } \\
\text { vegetais }\end{array}$ & $\begin{array}{c}\text { Não contendo } \\
\text { extratos vegetais }\end{array}$ \\
\hline E. coli & 1250,0 & 2500,0 & 1250,0 \\
S. aureus & 312,5 & 2500,0 & 1250,0 \\
B. subtilis & 312,5 & 625,0 & 625,0 \\
E. faecalis & 625,0 & 2500,0 & 1250,0 \\
P. aeruginosa & 1250,0 & 1250,0 & 2500,0 \\
\hline
\end{tabular}


larmente por sua ação antimicrobiana (antifúngica e antibacteriana) e antiinflamatória. Foram isolados dois novos compostos do extrato metanólico da planta (dialdeídos ciclopentenos), que apresentaram atividade em estudos iniciais.

São ainda registrados dados sobre a atividade antimicrobiana de $P$. major (tanchagem) segundo Holetz et al. (2002) que realizaram a avaliação desta em treze espécies vegetais popularmente utilizadas no Brasil. Estes estudos avaliaram a sensibilidade de microorganismos (bactérias e fungos) através da determinação da CIM para os extratos hidroalcoólicos de P. major.

Concordando com os trabalhos citados, nossos resultados demonstraram atividade antibacteriana para as espécies vegetais consideradas.

Cowan (1999) relatou o uso de misturas de extratos vegetais objetivando a potencialização de atividades, como mostrou alguns estudos realizados com produtos utilizados na Índia.

Neste caso pode-se observar que não houve diferença significativa entre a ação do enxaguatório bucal contendo extratos vegetais e o produto sem extratos vegetais. Porém, a mistura de extratos considerada apresentou atividade antimicrobiana significativa e, portanto, estudos complementares devem ser realizados para a correta otimização dessa e, outras atividades, visando a obtenção de produtos cosméticos eficazes para higiene bucal.

\section{CONCLUSÕES}

Os resultados farmacognósticos obtidos para a identificação de flavonóides, taninos, saponinas e alcalóides estão de acordo com o histórico das drogas vegetais estudadas. Conclui-se que os testes empregados foram suficientes para os estudos de pré-formulação, ressaltando as prováveis ações antiinflamatórias e adstringentes (flavonóides e taninos) e/ou anti-sépticas (taninos).

Pelos resultados obtidos para a formulação do enxaguatório bucal, conclui-se que o mesmo apresenta sabor aceitável e agradável, com ausência de precipitados, mantendo-se a concentração desejada de extratos vegetais.

No estudo da atividade antibacteriana, os microorganismos testados podem ser considerados sensíveis nas concentrações estudadas. Conclui-se que os extratos hidroalcoólicos das espécies vegetais apresentam atividade principalmente sobre bactérias Gram-positivas.

São necessários estudos complementares de atividade antimicrobiana para confirmar a eficácia deste produto e sua utilização para a prevenção e tratamento das doenças periodontais.

\section{ABSTRACT}

\section{Herbal extracts in an experimental mouthwash: pharmacognostics analysis and antibacterial activity}

In this study, herbs and hidroalcoholic extracts of Nasturtium officinale, Rosmarinus officinalis, Tabebuia impetiginosa, Plantago major and Achillea millefollium, were investigated for pharmacognostics analysis (flavonoids, alkaloids, tanins, saponins and antraquinones) and antibacterial activity (against Staphylococcus aureus, Bacillus subtilis, Escherichia coli, Enterococcus faecalis $e$ Pseudomonas aeruginosa). In vitro antibacterial studies were carried by the disc diffusion method, hole plate and tamplate. The minimum inhibitory concentration (MIC) values were determinated by broth dilution method. The extracts were incorporated in mouthwash for periodontal diseases treatment. The pharmacognostics studies showed that herbs and extracts have substances groups described in literature. The antibacterial studies showed that extracts and mouthwash have some activity against all considered bacteria. S. aureus and B. subtilis showed, apparently, to be species more susceptible. Investigation of the MIC showed $312,5 \mu \mathrm{L} / \mathrm{mL}-1250 \mu \mathrm{L} / \mathrm{mL}$ for extracts and $625 \mu \mathrm{L} / \mathrm{mL}$ $2500 \mu \mathrm{L} / m L$ for mouthwash. The studies served as initial quality control of the obtained cosmetic, enhancing antiinflammatory (flavonoids) and/or antibacterial activities (tanins). However, new studies are necessary to confirm the cosmetic efficacy for treatment periodontal diseases.

UNITERMS: Nasturtium. Rosmarinus. Tabebuia. Plantago. Achillea. Mouthwashes/antibacterial activity.

\section{REFERÊNCIAS BIBLIOGRÁFICAS}

ALMEIDA, R. Plantas Medicinais Brasileiras - conhecimentos populares e científicos. São Paulo: Hemus Editora Ltda, 1993. 341p.

BENDAZZOLI, W.S. Fitomedicamentos: perspectivas de resgate de uma terapia histórica. Mundo saúde; São Paulo, v.24, n.2, p.123-126, 2000.

COWAN, M. M. Plant products as antimicrobial agents. Cli. Microbiol. Rev. Middletown, v.12., n.4., p.564-582, 1999. 
FALKENBERG, M.B.; SANTOS, R.I.; SIMÕES, C.M.O. Introdução à análise fitoquímica. In: SIMOÕES, C.M.O.; SCHENKEL, E.P.; GOSMANN, G.; MELLO, J.C.P.; MENTZ, L.A.; PETROVICK, P.R. Famacognosia: da planta ao medicamento. $5^{\mathrm{a}}$ ed. Florianópolis: Editora da UFSC, 2003. cap.10, p.229-245.

FIGUEIREDO, C.R.L.V.; PINTO, L.P.; LINS, R.D.A.U.; GODOY, G.P.; MEDEIROS, K.B.; ALVES, R.D. Aspectos clínicos patológicos e etiopatogenéticos da doença periodontal: considerações atuais. Rev. Bras. Odontol., Rio de Janeiro. v.59, n.4, p.243-246, 2002.

FREITAS, P.C.D. Atividade antioxidante de espécies medicinais da família Piperaceae: Pothomorphe umbellata (L) Miq e Piper regnellii (Miq) CDC. São Paulo, 1999. 115p. [Tese de Doutorado. Faculdade de Ciências Farmacêuticas, Universidade de São Paulo].

GODA, Y.; HOSHINO, K.; AKIYAMA, II.; ISHIKAWA, T.; ABE, Y.; NAKAMURA, T.; OTSUKA, H. Constituents in watercress: inhibitors of histamine release from RBL2H3 cells. Biol. Pharm. Bull, Tokyo, v.22, n.12, p.13191326, 1999.

HOLETS, F.B.; PESSINI, G.L.; SANCHES, N.S.; CORTEZ, D.A.G.; NAKAMURA, C.V.; DIAS FILHO, B.P. Screening of some plants used in the brazilian folk medicine for the treatment of infectious diseases. Mem. Inst. Oswaldo Cruz, Rio de Janeiro, v. 97, n.7, p.10271031, 2002.

KOYAMA, J.; MORITA, I.; TAGAHARA, K.; HIRAI, K. I. Cyclopetene dialdehydes from Tabebuia impetiginosa. Phytochemistry, New York, v.53, p.869-872, 2000.

KRIVENKO, V. V., POTEBNIA, G.P., LOIKO, V.V. Experience in treating digestive organ diseases with medicinal plants. Vrach Delo, Kiev Izdatelstvo Zodorovia, Bratislava, v.3, p.76-78, 1989.

LORENZI, F.J.H.; MATOS, F. J. A. Plantas Medicinais do Brasil - nativas e exóticas. Nova Odessa: Instituto Plantarum de Estudos da Flora Ltda, 2002. 512p.

MARCANTONIO, J.E.; SANTOS, F.A. Avaliação das condições e necessidades de tratamento periodontal em escolares da zona rural, da região noroeste do estado de São Paulo - Brasil. Rev. Odontol. UNESP, Araraquara, v.27, n.2, p.449-458, 1998.
MATOS, F.J. de A. Plantas Medicinais - Guia de seleção e emprego de plantas usadas em fitoterapia no nordeste do Brasil. 2.ed. Fortaleza: Imprensa Universitária UFC, 2000. 344p.

MELLO, J.C.P.; CORTEZ, D.A.G.; CARDOSO, M.L.C. Análise fitoquímica preliminar. Maringá: Universidade Federal de Maringá, 1997. p.12-19. (Apostila de aulas práticas da disciplina de Farmacognosia).

MONTEIRO, A.M.D.; ARAÚJO, R.P.C.; GOMES FILHO, I.S. Diabetes Mellitus tipo 2 e doença periodontal. Rev. Gaúcha Odontol., Porto Alegre, v.50, n.1, p.50-54, 2002.

NASCIMENTO, G.G.F.; LOCATELLI, J.; FREITAS, P.C.D. Antibacterial activity of plant extracts and phytochemicals on antibiotic-resistant bacteria. Braz. J. Microbiol., Rio de Janeiro, v.31, n.4, p.247-256, 2000 .

OLIVEIRA, D.C.; ROSELL, F.L.; SAMPAIO, J.E.C.; RODRIGUES JÚNIOR, A.L. Redução do índice de placa com Listerine: avaliaçäo do índice de placa em relação ao uso de Listerine e/ou escovação. Rev. Gaúcha Odontol. Porto Alegre, v.46, n.2, p.101-104, 107-108, 1998.

OPPERMANN, R.V.; KUCHNBECKER, C.R. Periodontia Ciência e Clínica. São Paulo: Editora Artes Médicas, 2001. 458p.

PEREIRA, A.C.; ROSA, A.G.F.; BICUDO PEREIRA, I.M.T. O processo educativo na prevenção da doença periodontal em crianças. Rev. Bras. Saúde Esc., São Paulo v.3, p.44-48, 1994.

PRISTA, L. N.; ALVES, A. C.; MORGADO, R. Tecnologia Farmacêutica. $5^{\text {a }}$ ed. Lisboa: Fundação Calouste Gulbenkian, 1995. 786p.

REY, L. Dicionário de termos técnicos de Medicina e Saúde. Rio de Janeiro: Guanabara Koogan, 1999. 825p.

RUBIRA, I.R.F. Pesquisa de bactérias bucais em amostras de placa subgengival de individuos com periodonto normal e de portadores de periodontite através da técnica do "Slot Immunoblot". Bauru, 1993. 113p. [Tese de Doutorado, Faculdade de Odontologia, Universidade de São Paulo, Bauru]. 
SAMUELSEM, A.B. The traditional uses, chemical constituents and biological activities of Plantago major L. Areview. J. Ethnopharmacol., Lausanne, v.71, n.1-2, p. 1-21, 2000.

SÖKMEN,A.; ÜLNLÜ, G. V.; POLISSIOU,M.; DAFERERA, D.; SÖKMEN, M.; DÖNMEZE. Antimicrobial activity of essential oil and methanol extracts of Achillea sintenisii Hub. Mor. (Asteraceae). Phytotherapy Res., London. v.17, p.1005-1010, 2003.

TESKE, M.; TRENTINI, A.M.M. Compêndio de Fitoterapia, $4^{a}$ ed. Curitiba: Herbarium - Laboratório Botânico, 1995. $317 \mathrm{p}$.
TREVIZANI, L.M.M. Efeito do gel dentifrício formulado com extratos vegetais em doenças periodontais. Araraquara, 2002. 103p. [Dissertação de Mestrado. Faculdade de Ciências Farmacêuticas, Universidade Estadual Paulista].

WILLERSHAUSEN, B; GRUBER, I.; HAMM, G. Índice de placa e sangramentos gengivais: a influência de ingredientes herbários. Rev. Assoc. Paul. Cir. Dent., v.48, n.3, p.1335-1340, 1994.

Recebido para publicação em 31 de janeiro de 2005. Aceito para publicação em 26 de abril de 2006. 